\title{
Catalyst Interface Engineering for Improved 2D Film Lift-Off and Transfer
}

\begin{abstract}
Wang, Ruizhi; Whelan, Patrick Rebsdorf; Braeuninger-Weimer, Philipp; Tappertzhofen, Stefan; Alexander-Webber, Jack A; Van Veldhoven, Zenas A.; Kidambi, Piran R; Jessen, Bjarke Sørensen; Booth, Tim ; Bøggild, Peter
\end{abstract}

Total number of authors:

11

Published in:

A C S Applied Materials and Interfaces

Link to article, DOI:

10.1021/acsami.6b11685

Publication date:

2016

Document Version

Publisher's PDF, also known as Version of record

Link back to DTU Orbit

Citation (APA):

Wang, R., Whelan, P. R., Braeuninger-Weimer, P., Tappertzhofen, S., Alexander-Webber, J. A., Van Veldhoven, Z. A., Kidambi, P. R., Jessen, B. S., Booth, T., Bøggild, P., \& Hofmann, S. (2016). Catalyst Interface Engineering for Improved 2D Film Lift-Off and Transfer. A C S Applied Materials and Interfaces, 8(48), 33072-33082. https://doi.org/10.1021/acsami.6b11685

\section{General rights}

Copyright and moral rights for the publications made accessible in the public portal are retained by the authors and/or other copyright owners and it is a condition of accessing publications that users recognise and abide by the legal requirements associated with these rights.

- Users may download and print one copy of any publication from the public portal for the purpose of private study or research.

- You may not further distribute the material or use it for any profit-making activity or commercial gain

- You may freely distribute the URL identifying the publication in the public portal 


\section{Catalyst Interface Engineering for Improved 2D Film Lift-Off and Transfer}

Ruizhi Wang, ${ }^{\dagger}$ Patrick R. Whelan, ${ }^{\ddagger}$ Philipp Braeuninger-Weimer, ${ }^{\dagger}$ Stefan Tappertzhofen, ${ }^{\dagger}$ Jack A. Alexander-Webber, ${ }^{\dagger}$ Zenas A. Van Veldhoven, ${ }^{\dagger, \S}$ Piran R. Kidambi, ${ }^{\|}$Bjarke S. Jessen, ${ }^{\ddagger}$ Timothy Booth, ${ }^{\ddagger}$ Peter Bøggild, ${ }^{\ddagger}$ and Stephan Hofmann*, ${ }^{\dagger}$

${ }^{\dagger}$ Department of Engineering, University of Cambridge, Cambridge CB3 OFA, United Kingdom

${ }^{\ddagger}$ Center for Nanostructured Graphene (CNG), DTU Nanotech, Technical University of Denmark, DK-2800, Kongens Lyngby, Denmark

${ }^{\S}$ Cambridge Graphene Centre, University of Cambridge, 9 JJ Thomson Avenue, Cambridge CB3 0FA, United Kingdom

"Department of Mechanical Engineering, Massachusetts Institute of Technology, Cambridge, Massachusetts 02139, United States

\section{Supporting Information}

ABSTRACT: The mechanisms by which chemical vapor deposited (CVD) graphene and hexagonal boron nitride (h-BN) films can be released from a growth catalyst, such as widely used copper $(\mathrm{Cu})$ foil, are systematically explored as a basis for an improved lift-off transfer. We show how intercalation processes allow the local $\mathrm{Cu}$ oxidation at the interface followed by selective oxide dissolution, which gently releases the 2D material (2DM) film. Interfacial composition change and selective dissolution can thereby be achieved in a single step or split into two individual process steps. We demonstrate that this method is not only highly versatile but also yields graphene and h-BN films of high quality regarding surface contamination, layer coherence, defects, and electronic properties, without requiring additional post-transfer annealing. We highlight how such transfers rely on targeted corrosion at the catalyst interface and discuss this in context of the

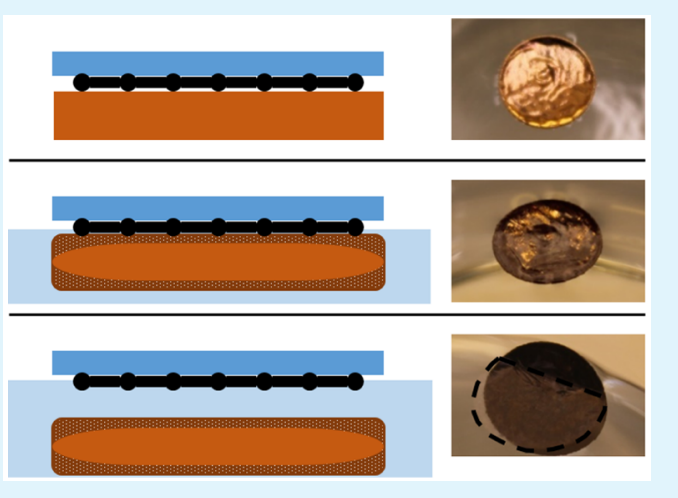
wider CVD growth and 2DM transfer literature, thereby fostering an improved general understanding of widely used transfer processes, which is essential to numerous other applications.

KEYWORDS: $2 D$ materials, CVD, transfer, catalyst, graphene, $h-B N$

\section{INTRODUCTION}

Chemical vapor deposition (CVD) has emerged in recent years as the most promising method for the controlled and scalable synthesis of high quality films of $2 \mathrm{D}$ materials (2DM) such as graphene $^{1,2}$ and hexagonal boron nitride (h-BN)., While much recent attention has focused on 2DM growth mechanisms on the typically used catalyst materials, ${ }^{5-11}$ many applications require transfer of the 2DM films away from the growth substrate, which has become a serious bottleneck. ${ }^{12,13} \mathrm{~A}$ widely used method for transfer is to release the $2 \mathrm{DM}$ by etching away the complete catalyst foil or film, ${ }^{14,15}$ generally referred to as wet transfer. However, this method can lead to considerable contamination of the $2 \mathrm{DM}$, be it by the polymer, process chemicals, or metal. ${ }^{16}$ In addition, it results in increased cost and sustainability concerns for industrial manufacturing, as the catalyst material becomes a waste product.

Approaches to overcome the adhesion between the 2DM film and the CVD catalyst have been developed to preserve the catalyst and to allow transfer from materials that cannot be easily dissolved. ${ }^{17,18}$ A seemingly simple method, as a basis of a so-called dry transfer, is to attach an adhesive layer to the $2 \mathrm{DM}$ and to delaminate it by applying mechanical force. ${ }^{17,19} \mathrm{~A}$ key concern is to sufficiently weaken the $2 \mathrm{DM} /$ catalyst interaction to permit the transfer of large areas without tearing and introduction of holes/defects into the atomically thin films. In order to aid their release for a wide range of catalyst materials, several electrochemical methods have been introduced. In the case of bubbling transfer, the enhanced 2DM film delamination is mainly attributed to the generation of hydrogen at its catalyst interface. ${ }^{18,20,21}$ While this method can be relatively fast, it can significantly damage 2DM films due to the generation of gas bubbles at the interface. ${ }^{22}$ Another electrochemical method that has been introduced recently for the transfer of graphene grown on $\mathrm{Cu}$ is oxidative delamination transfer (ODT) ${ }^{23}$ It enables transfer through the oxidation and following reduction of the copper surface. In addition to the above-mentioned methods, a range of iterations on the chemical modification of the 2DM/ catalyst interface have been reported to achieve a better combination of speed and quality of the transfer process. These include for instance water/air exposure in the case of graphene/

Received: September 14, 2016

Accepted: November 10, 2016

Published: November 10, 2016 
(a)
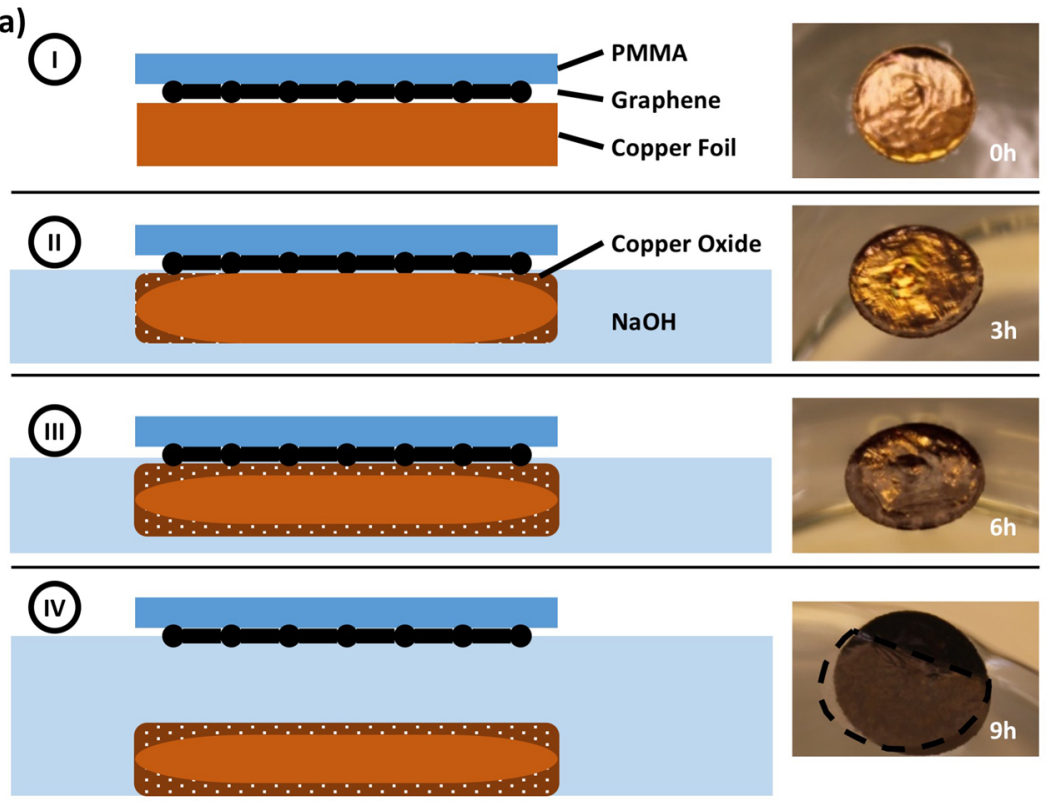

(b)

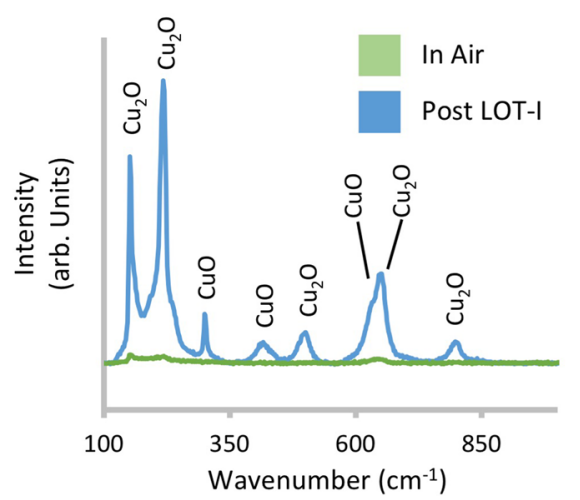

Figure 1. (a) Schematic representation of LOT-I (left) and photographs of a sample of $1 \mathrm{~cm}$ diameter floating on sodium hydroxide (NaOH) taken during the transfer process (right). Graphene as grown on $\mathrm{Cu}$ is covered with a support layer (I). The sample is floated on $\mathrm{NaOH}$, upon which oxidation of the interfacial $\mathrm{Cu}$ and the subsequent dissolution sets in (II-III). After an extended period, the whole interface layer is removed, and the graphene/PMMA stack will float freely on the liquid. For clarity, the edge of the detached film is indicated in IV. (b) Raman spectra of the Cu foil after LOT-I taken with a $488 \mathrm{~nm}$ laser. The peaks related to $\mathrm{Cu}_{2} \mathrm{O}\left(154 \mathrm{~cm}^{-1}, 220 \mathrm{~cm}^{-1}, 492 \mathrm{~cm}^{-1}, 633 \mathrm{~cm}^{-1}, 786 \mathrm{~cm}^{-1}\right)$ and $\mathrm{CuO}_{\left(300 \mathrm{~cm}^{-1}, 340\right.}$ $\left.\mathrm{cm}^{-1}, 635 \mathrm{~cm}^{-1}\right)^{41}$ are indicated.

$\mathrm{Cu}^{24-26}$ and the use of a high $\mathrm{pH}$ solution to release graphene from platinum $(\mathrm{Pt}) .^{27}$

While a diverse body of literature on improved 2DM transfer is emerging, there is currently very little fundamental understanding of the underlying mechanisms of transfer. Much progress has been made in understanding the role of the different catalysts and the 2DM interface during the growth process. $^{28,29}$ Noticeable advances have also been achieved regarding the understanding of postgrowth passivation and corrosion applications. ${ }^{30-32}$ However, this knowledge has not yet been used in the context of 2DM transfer. Neither 2DM/ catalyst material specific mechanisms nor the categorization into general cases such as weakly and strongly interacting catalysts have been applied to transfer in any detailed level. The development of holistic approaches connecting growth and transfer is critical for future 2DM manufacturing and device integration.

Here, we demonstrate how we can draft improved methods of transfer based on the understanding of the properties of the $2 \mathrm{DM} /$ catalyst interface. The goal of this study thereby is not to target record electrical mobility or other 2DM properties.
Instead, we seek to understand the mechanisms involved in $2 \mathrm{DM}$ transfer and to find a general approach to design and improve transfer methods in particular regarding control and reproducibility while minimizing $2 \mathrm{DM}$ contamination. We focus on $2 \mathrm{DM}$ grown on $\mathrm{Cu}$, as this is currently the most widely used catalyst. The starting point of our rationale is the weak interaction between $2 \mathrm{DMs}$, such as graphene and h-BN, and $\mathrm{Cu}$, which we previously explored in terms of CVD growth. $^{10,33}$ Thus, gases ${ }^{10}$ and also liquids ${ }^{34,35}$ can intercalate into the $\mathrm{Cu} / 2 \mathrm{DM}$ interface. This effect is highly undesired when it comes to surface passivation and corrosion protection..$^{30,32}$ In the context of transfer, however, it offers a new pathway toward delamination. Through intercalation, it is possible to access the $2 \mathrm{DM} /$ catalyst interface, to change its chemical composition, and to remove for instance interfacial oxide layers. In this way, delamination is achieved by targeted corrosion at the interface. This mechanism allows for a method of transfer, which we refer to here as lift-off transfer (LOT). In general, there are two pathways for LOT, either involving both interface oxidation and selective removal in a single (LOT-I) or two different process steps (LOT-II). This approach allows us 
(a)
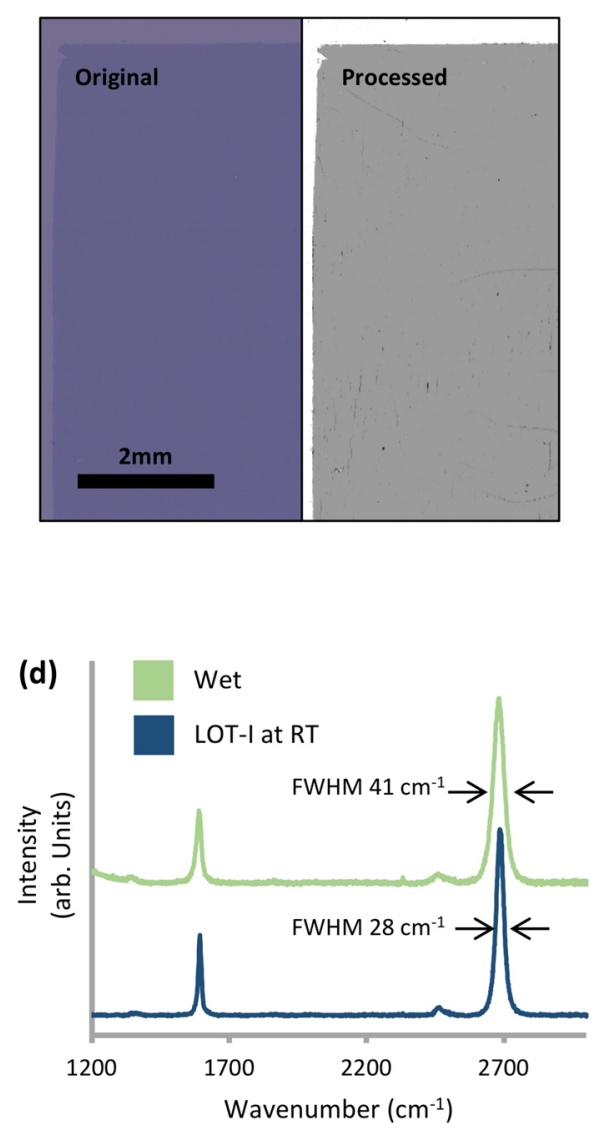

(b) Single Layer Graphene (\% of total Surface)

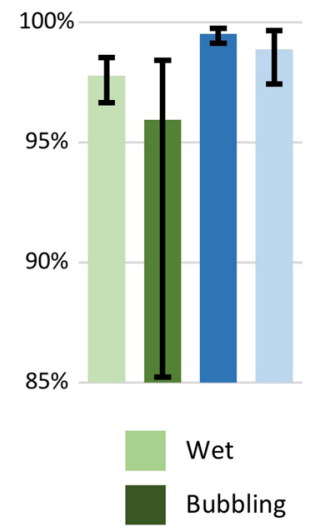

(e)

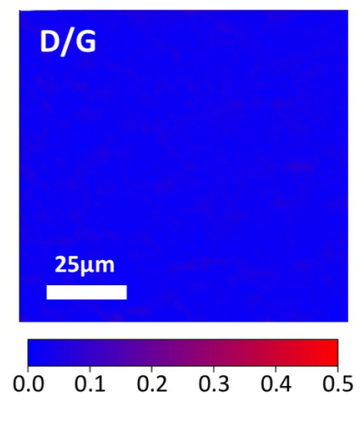

(c) Residues (\% of total Surface)

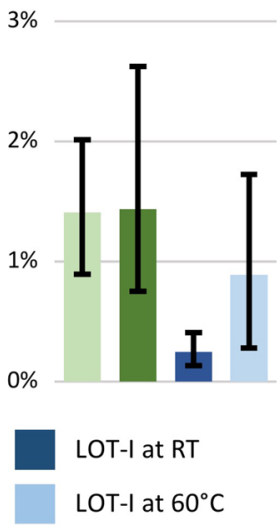

(f)

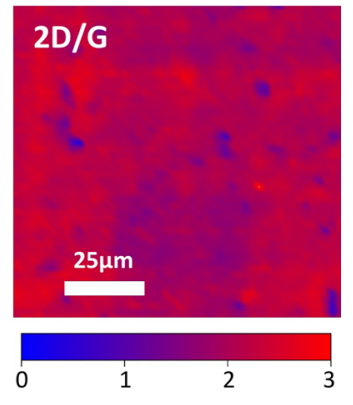

Figure 2. (a) Left frame, graphene on a $90 \mathrm{~nm} \mathrm{SiO} 2 / \mathrm{Si}$ wafer after LOT-I transfer at RT. Right frame, the same image as on the left after automated software analysis. Residue spots are more easily visible (dark dots). (b,c) Quantitative analysis of the surface composition as derived from the automated detection system. A large number of images from different samples were analyzed regarding its composition. Plot b shows the coverage of single layer graphene; plot c presents the surface area covered by residues. The bar represents the median, the error bars the first and third quartile. (d) Raman spectrum of graphene obtained through wet transfer and LOT-I at RT. (e,f) Raman maps of graphene after LOT-I transfer. Map e presents the $\mathrm{D} / \mathrm{G}$ ratio (average $<0.03$ with a standard deviation $<0.01$ ) and map f, the $2 \mathrm{D} / \mathrm{G}$ ratio (average 2.25 with a standard deviation of 0.26 ). All measurements were taken with a $532 \mathrm{~nm}$ laser.

to demonstrate the transfer of graphene and h-BN single layer films from $\mathrm{Cu}$. The resulting layers are of high quality regarding surface residues, layer coherence, and electronic properties. Furthermore, the catalyst is retained. We discuss our results in the context of the latest literature on CVD growth, corrosion/ passivation, and 2DM transfer. We thereby foster an improved general understanding of transfer processes, which is of crucial importance to many applications.

\section{RESULTS}

Figure 1a outlines the LOT-I transfer process, both schematically and by corresponding optical photographs of a graphene/ $\mathrm{Cu}$ sample throughout transfer. As a model system, we use a simple $\mathrm{Cu}$-catalyzed CVD process that gives a continuous single layer graphene film with an average graphene domain size on the order of $10-20 \mu \mathrm{m}$ (see Experimental Methods section). ${ }^{10,36}$ After the growth period, the samples are stored under atmospheric conditions for up to a month before transfer. It is well-known that storing graphene on $\mathrm{Cu}$ for extended periods can lead to local $\mathrm{Cu}$ oxidation and contamination with adsorbents. ${ }^{33,37}$ Our process here is designed to minimize the effects of uncontrolled factors. The transfer process starts by coating the samples with a polymer support layer [in the given case poly(methyl methacrylate)
(PMMA)] and then floating it on top of a $1 \mathrm{M}$ solution of sodium hydroxide $(\mathrm{NaOH})$. It is important to note that removal of backside graphene is not necessary for the given process. As shown in the photographs in Figure $1 \mathrm{a}$, the $\mathrm{Cu}$ foil changes its color at the edge of the sample after a short time on $\mathrm{NaOH}$, which we relate to $\mathrm{Cu}$ oxidation. ${ }^{38}$ Upon extended exposure, the oxidation front moves inward toward the center of the sample. At room temperature (RT), a graphene film of 1 $\mathrm{cm} \times 1 \mathrm{~cm}$ will detach completely from the $\mathrm{Cu}$ growth substrate after roughly $12 \mathrm{~h}$. When the temperature is raised to $60{ }^{\circ} \mathrm{C}$, delamination occurs after only $2-3 \mathrm{~h}$. We relate the decrease in process time to an acceleration of the same underlying mechanism as the progression of the oxidation front and overall appearance of the foil remain the same. After rinsing in water, the layer is transferred onto the destination substrate, dried, and then dipped into acetone and isopropanol (IPA) for polymer removal (see Experimental Methods section for details).

LOT-I is based on two main processes. The first is the intercalation of the base into the interface between the 2DM and $\mathrm{Cu}$, which leads to local $\mathrm{Cu}$ oxidization. The following selective dissolution of the copper oxide gently releases the 2DM film, which remains floating on the surface of the liquid. The proposed mechanism of LOT-I will be presented in greater 

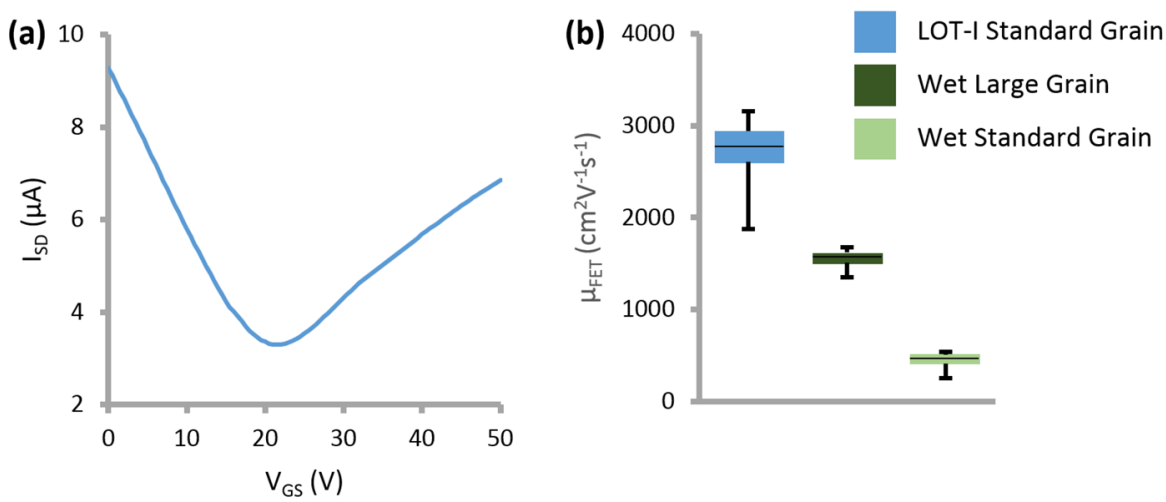

Figure 3. (a) Transfer curve of FET with channel dimensions of $25 \mu \mathrm{m} \times 25 \mu \mathrm{m}$ and $300 \mathrm{~nm} \mathrm{SiO}_{2}$ backgate oxide. The backgate voltage is swept from $V_{\mathrm{GS}}=0 \mathrm{~V}-60 \mathrm{~V}$, while applying a drain-source voltage $V_{\mathrm{DS}}$ of $10 \mathrm{mV}$ and measuring the drain current $I_{\mathrm{D}}$. The hole mobility calculated using the maximum transconductance and a gate capacitance of $11.6 \times 10^{-9} \mathrm{~F} \mathrm{~cm}^{-2}$ is $3046 \mathrm{~cm} \mathrm{~V}^{-1} \mathrm{~s}^{-1}$. The measurement was taken in the atmosphere after device fabrication without an additional annealing step. (b) FET mobility $\mu_{\mathrm{FET}}$ of identically fabricated devices except of the transfer method. The error bars denote the maximum and minimum values; the box represents the first and third quartile.

detail in the Discussion section. It is important to note that this reaction is not just limited to $\mathrm{NaOH}$. In order to verify this claim, LOT-I was performed using identical processes and samples as described above, but with a $50 \%$ weight to volume potassium hydroxide $(\mathrm{KOH})$ solution. Similar to the standard process using $\mathrm{NaOH}$, the graphene/polymer film detached after $12 \mathrm{~h}$ at room temperature. However, the samples showed a higher degree of contamination post-transfer, most likely as $\mathrm{KOH}$ is known to attack PMMA. ${ }^{39}$

To support our model that the radial inward color change shown in Figure la corresponds to $\mathrm{Cu}$ oxidation, the surface composition of the $\mathrm{Cu}$ foil post-transfer was investigated using Raman spectroscopy. For reference, measurements were undertaken on an identical sample, which was grown at the same time and stored under identical conditions, but not floated on $\mathrm{NaOH}$. The reference sample is thus still covered by graphene. However, any potential presence of $\mathrm{Cu}$ would still be visible using Raman spectroscopy, as graphene has a very low absorption throughout the whole visible range and as there are no peaks in this spectral region assigned to graphene. ${ }^{40}$ The results of the measurement are given in Figure $1 \mathrm{~b}$. The postLOT $\mathrm{Cu}$ foil displays a set of peaks that can be assigned to $\mathrm{Cu}_{2} \mathrm{O}\left(154 \mathrm{~cm}^{-1}, 220 \mathrm{~cm}^{-1}, 492 \mathrm{~cm}^{-1}, 633 \mathrm{~cm}^{-1}, 786 \mathrm{~cm}^{-1}\right)$ and $\mathrm{CuO}\left(300 \mathrm{~cm}^{-1}, 340 \mathrm{~cm}^{-1}, 635 \mathrm{~cm}^{-1}\right){ }^{38,41}$ These peaks are absent or very weak in the reference samples that have been exposed to air for a limited amount of time. ${ }^{10}$ The result confirms the increased oxidation due to exposure to a base. Furthermore, it shows that while copper oxide is dissolved during transfer, the rate of oxidation is much higher than its dissolution, and copper oxide hence remains on the foil posttransfer.

In order to quantify the cleanliness and coverage of the graphene layer after transfer, software-aided optical and Raman analysis was performed. The results are given in Figure 2. The details of the optical mapping method, which has been used previously to assess graphene layers after transfer, ${ }^{23}$ can be found in the Experimental Methods section. In short, a number of optical images covering the complete graphene layer are taken. Custom-made software, which is precalibrated for graphene transferred onto $90 \mathrm{~nm} \mathrm{SiO}$ due to optimal interference contrast, analyzes every pixel of each image. On the basis of the contrast, it discerns whether a pixel represents graphene, $\mathrm{SiO}_{2}$, or other particles, which are then categorized as residues. This provides a platform to quantify the coverage and cleanliness of graphene after transfer. Figure 2a shows an image consisting of multiple smaller pictures. It was taken by the optical microscope and stitched together during post processing. For the sake of comparison, the image after software analysis is also shown. We analyzed three samples of each of the following methods to transfer continuously grown layers of graphene: LOT-I at RT, LOT-I at $60{ }^{\circ} \mathrm{C}$, wet transfer, and bubbling transfer (see Experimental Methods section for details). The latter two are widely used standard techniques and serve as references. Figure $2 b$ and $c$ show the quantitative results based on the analysis of around 50-100 images across the whole area of about $1 \mathrm{~cm}^{2}$ of each respective transferred layer. The fraction of surface covered by pristine single layer graphene after LOT-I at RT is about $99.5 \%$. Residues are found on less than $0.25 \%$ of the surface. The graphene cleanliness and coherence slightly deteriorates when the temperature of the transfer is increased. Nonetheless, $98.9 \%$ of the surface area consists of single layer graphene (SLG), and only $0.8 \%$ is composed of other residues. We suggest the graphene quality decrease for LOT-I at elevated temperatures is due to the impact of a hot alkaline solution on the polymer support layer. On the basis of a similar argument, we point out that reducing the reactivity of the etchant and, as proposed previously, ${ }^{22}$ suppressing the onset of violent bubble formation could lead to improved, though slower, transfer for wet transfer and bubbling, respectively.

Nonetheless, LOT outperforms wet transfer (97.8\% SLG and $1.4 \%$ other residues) and bubbling (96\% SLG and $1.4 \%$ residues). The spread of residues is also of noticeable difference for the latter two methods. Bubbling results in large local variations of residues, i.e., regions without vs regions with accumulation of residues, as evidenced by the large standard deviation. We suggest that this is linked to the local damage that the film sustains during the violent transfer process, ${ }^{23}$ which also results in a lower SLG coverage due to holes.

Recent literature highlights that the full width at halfmaximum (fwhm) of the $2 \mathrm{D}$ peak is an indicator for nanometer-scale strain variations, which negatively impact the electronic properties of graphene. ${ }^{42}$ Figure $2 \mathrm{~d}$ shows a comparative Raman analysis of the graphene transferred by LOT-I at RT and by standard wet transfer. Notably for the LOT-I process the fwhm of the $2 \mathrm{D}$ peak is only $28 \mathrm{~cm}^{-1}$. This 
(a)
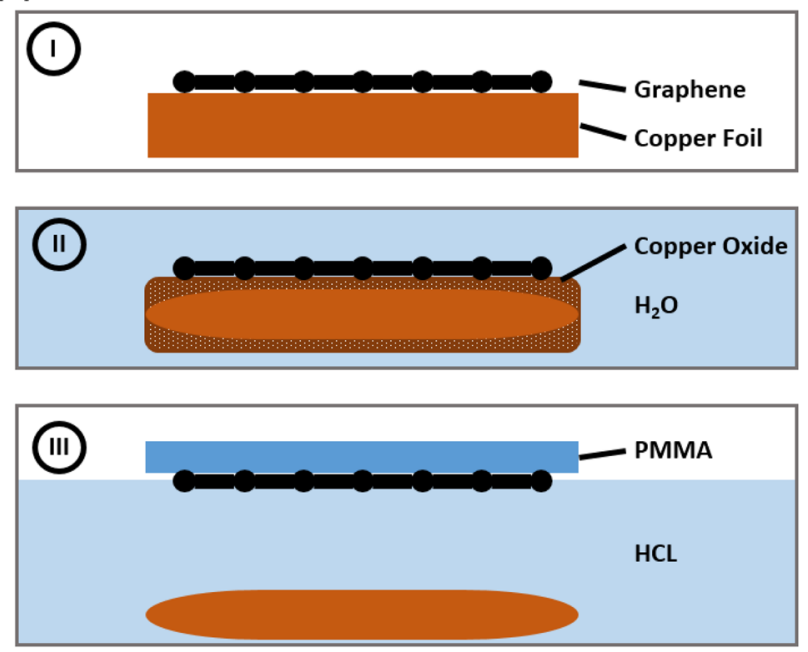

(b)

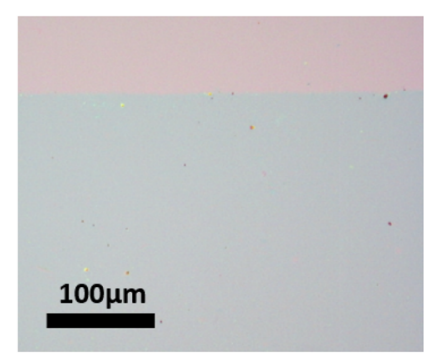

(c)

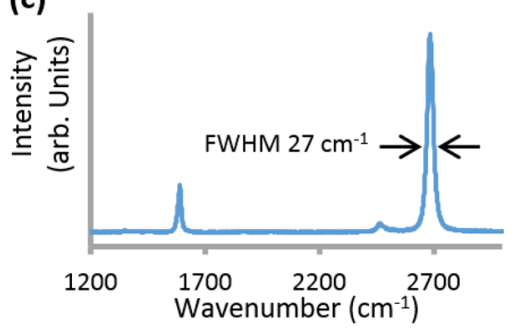

Figure 4. (a) Process schematic of the LOT-II transfer. Graphene as grown on $\mathrm{Cu}$ is immersed in water at $50{ }^{\circ} \mathrm{C}$, which leads to the formation of $\mathrm{Cu}$ oxide (frame I-II). The sample is then floated on HCL, which dissolves the Cu oxide and releases the graphene/PMMA layer. (b) Optical image of graphene transferred by LOT-II onto $300 \mathrm{~nm} \mathrm{SiO} 2 / \mathrm{Si}$. (c) Raman spectrum of two-step LOT graphene taken with a 532 nm laser.

is well below the average fwhm of samples obtained through wet transfer in our own experiments $\left(41 \mathrm{~cm}^{-1}\right)$ as well as compared to previous studies, which report a value of around $35 \mathrm{~cm}^{-1} \cdot{ }^{26}$ In fact, only dry transfer by directly picking up the graphene flake with a layer of $\mathrm{h}-\mathrm{BN}$ and placing this heterostructure onto $\mathrm{SiO}_{2}$ leads to a similar fwhm of about $25 \mathrm{~cm}^{-1} \cdot{ }^{42}$ In order to assess the graphene quality over a larger area, Raman maps of graphene transferred by LOT-I, including the $D / G$ and $2 D / G$ ratios, are presented in Figure 2e and f. For reference, the same measurements were performed on samples obtained through wet transfer. The resulting maps are given in Figure S1. The average D/G peak intensity ratio for LOT-I transfer is below 0.03 (standard deviation $<0.01$ ), and the $2 \mathrm{D}$ peak is well fitted with a single Lorentzian. The measurement yields an average $2 \mathrm{D} / \mathrm{G}$ ratio of 2.25 , which confirms uniform monolayer graphene across the whole measured area.

Figure 3a shows an exemplary individual device transfer curve, and Figure $3 \mathrm{~b}$ compares the influence of different transfer methods on the electrical properties of graphene. A large number of two-terminal graphene devices with different dimensions were fabricated on $300 \mathrm{~nm} \mathrm{SiO}_{2} / \mathrm{Si}$ support for field-effect transistor (FET) measurements (see Experimental Methods section; Figure S2 shows an optical image of an exemplary individual device). Statistics on the FET mobility are presented in Figure 3. A total of 15 devices fabricated with LOT-I were characterized. As a comparison, identical devices using traditional transfer methods were made. However, as bubbling transfer leads to a significant amount of holes, which is highly challenging for patterning with photolithography, we focused on wet transfer of standard $(10-25 \mu \mathrm{m})$ and large grain size $(200-400 \mu \mathrm{m})$ only (see Experimental Methods section). The results of Figure 3 highlight that the most significant impact on electrical transport arises from nonideal transfer methods and not from the inherent quality of graphene. LOT-I transferred graphene yields a median hole mobility of $2770 \mathrm{~cm} \mathrm{~V}^{-1} \mathrm{~s}^{-1}$. This result is significantly higher than for the wet-transferred samples, which only show $1570 \mathrm{~cm}$ $\mathrm{V}^{-1} \mathrm{~s}^{-1}$ for large grain size and $461 \mathrm{~cm} \mathrm{~V}^{-1} \mathrm{~s}^{-1}$ for standard grain size graphene. In the case of wet transfer, we suggest that acid induced polymer cross-linking ${ }^{16,43}$ and preferential residue accumulation along the grain boundaries ${ }^{44-46}$ are the main contributors to the diminished performance. In particular, the case of cross-linking is avoided in the LOT-I process, as the samples are only in contact with a $\mathrm{NaOH}$ solution. In addition to the FET measurement, it is possible to derive the contact resistance by comparing devices with different channel lengths due to the high uniformity of devices. In Figure S3, the channel resistance at $0 \mathrm{~V}$ gate voltage is plotted against the channel length. We find a contact resistance of $4400 \Omega \mu \mathrm{m}$, which corresponds to the reported minimum for optical lithography. ${ }^{47}$

Thus far, our study has focused on the LOT-I process. As mentioned earlier, based on the rationale of transforming the catalyst interface composition and selectively removing an asformed interface layer, another approach is possible. The method which we refer to here as LOT-II is depicted schematically in Figure 4a. LOT-II essentially splits the interface oxidation of the catalyst and the dissolution of the oxide layer into two separate processes. There are many ways to oxidize $\mathrm{Cu}$ at the interface. As oxygen can easily intercalate into the interface between $\mathrm{Cu}$ and graphene, ${ }^{33}$ a simple method is to leave the sample under ambient conditions for an extended period. $^{26,30}$ However, in order to speed up the process, we generate $\mathrm{Cu}$ oxide by immersing samples in water at $50{ }^{\circ} \mathrm{C}$ for 12 h. $^{34}$ The samples are then spin-coated with PMMA and floated on hydrochloric acid, which was chosen because it attacks solely the $\mathrm{Cu}$ oxide but not $\mathrm{Cu}$ itself. Within a few minutes, the graphene/PMMA stack detaches itself from the $\mathrm{Cu}$ foil, which then sinks to the bottom of the beaker. The film can then be processed identically to LOT-I, i.e., transferring to the destination substrate, drying, and removing the support layer.

Figure $4 \mathrm{~b}$ shows an optical image of the graphene sample after transfer on $\mathrm{SiO}_{2}$. Our preliminary results indicate that LOT-II results in a higher degree of surface contamination, as shown by large particles on the sample that are completely absent for LOT-I. We relate this result to the impact of acids on polymers, which is known to be one of the main contributors to contamination in wet transfer. ${ }^{43}$ Nonetheless, the graphene is 
(a)

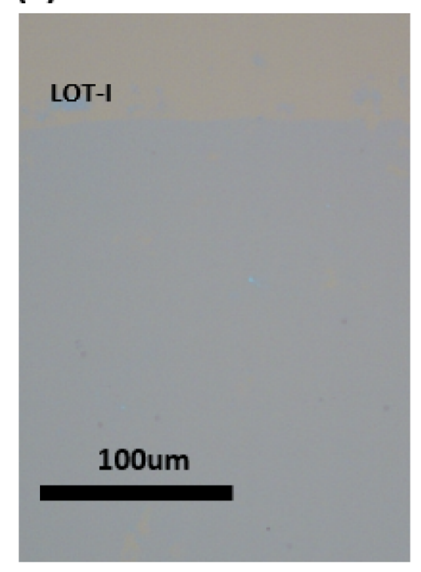

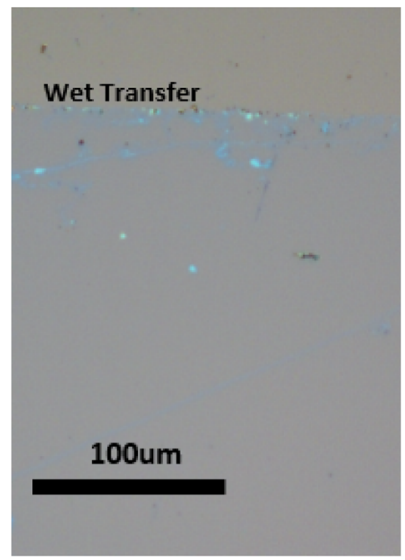

(b)

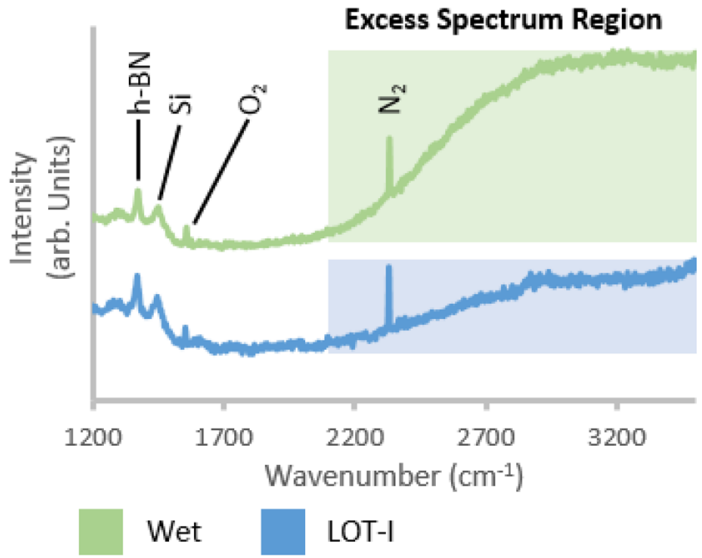

Figure 5. (a) Representative optical images of h-BN transferred by LOT-I and wet transfer for reference onto $90 \mathrm{~nm} \mathrm{SiO} / 2 / \mathrm{Si}$. (b) Raman spectra of h-BN after LOT-I and wet transfer onto $90 \mathrm{~nm} \mathrm{SiO} / 2 \mathrm{Si}$ taken with a $532 \mathrm{~nm}$ laser. The peaks of h-BN $\left(1371 \mathrm{~cm}^{-1}\right)$, silicon third order $\left(1449 \mathrm{~cm}^{-1}\right)$, oxygen $\left(1556 \mathrm{~cm}^{-1}\right)$, and nitrogen $\left(2331 \mathrm{~cm}^{-1}\right)^{48,56}$ are indicated in the plot. The shaded area ("Excess Spectrum Region") marks the region where a bulge in spectrum due to photoluminescence is to be expected in the case of increased organic contamination. ${ }^{49}$

still of good quality as shown by the absence of a significant D peak in the Raman spectrum given in Figure 4c. The $2 \mathrm{D}$ peak is well fitted by a single Lorentzian with a fwhm of only $27 \mathrm{~cm}^{-1}$, which is similar to samples transferred by LOT-I. We propose that the generation of a sufficiently thick interfacial $\mathrm{Cu}$ oxide, as given for LOT-I and LOT-II, decreases the nanometer-scale strain variations in the graphene layer on the substrate, which is a state that is retained after transfer. This finding suggests that preoxidizing the $\mathrm{Cu}$ interface prior to wet transfer could potentially also lead to a reduction of nanometer-scale variation post-transfer and thus improve the overall quality of the 2DM layer.

LOT transfer processes can also be applied to other 2D materials including h-BN, which, while being isostructural to graphene, is a wide band gap semiconductor and has otherwise distinct properties. ${ }^{3,5}$ This allows us to establish that, despite different 2DM properties, the main mechanisms of the LOT transfer are in fact quite similar. Here, we focus on continuous h-BN films with grain sizes of $1-5 \mu \mathrm{m}$, which are catalytically grown by CVD directly on $\mathrm{Cu} .{ }^{11}$

Following again the LOT-I process outlined in Figure 1a, the h-BN single layer on $\mathrm{Cu}$ is spin coated with PMMA, floated on $1 \mathrm{M} \mathrm{NaOH}$, rinsed, and then transferred to the desired substrate. Figure 5a shows optical images of LOT-I and wet transfer samples for comparison. Similar to graphene transfer, LOT-I results in a clean interface with no large visible particles. Figure $5 \mathrm{~b}$ presents Raman spectra of an as-transferred h-BN sample on $\mathrm{SiO}_{2}$ by LOT-I and wet transfer. In both cases, the Raman peak position at $1371 \mathrm{~cm}^{-1}$ indicates that the $\mathrm{h}-\mathrm{BN}$ is single-layered. ${ }^{48}$ Raman spectroscopy can be used to assess the contamination by organic residues of an h-BN film. Previous studies have shown that organic contaminants can lead to a significant broad luminescent background. ${ }^{49}$ In the spectra given in Figure 5b, it is apparent that wet transfer leads to an increased background in the region between about 2000 and $3500 \mathrm{~cm}^{-1}$, which can be related to residues. This result strongly suggests that LOT-I produces samples of improved cleanliness.

\section{DISCUSSION}

On the basis of our observations, the following paragraphs provide a detailed discussion on the proposed mechanisms of
LOT-I and -II. The transfer process consists of two distinct steps. The first is the intercalation of the solution into the interface and its oxidation. We mentioned previously that during LOT-I the PMMA/2DM/Cu stack is floated on an alkaline solution instead of being immersed. Thus, we assume intercalation only occurs from the edge of the sample. The second step is the dissolution of the interfacial oxide. Due to the presence of $\mathrm{Cu}$ oxide after transfer, we suggest that the rate of dissolution is smaller than the rate of oxidation.

The interface oxidation during LOT-I depends critically on how easily atmospheric oxygen can access the $2 \mathrm{DM} / \mathrm{Cu}$ interface. It has been shown that in the case of $2 \mathrm{DMs}$ on $\mathrm{Cu}$, gases and liquids will permeate into the interface. ${ }^{30,33}$ However, this is less due to direct permeation through the 2DM, but rather a result of intercalation through defects or the edges of the sample. ${ }^{34,35}$ Thus, we suggest that, while not being perfect, 2DMs act as a permeation barrier for atmospheric oxygen. In contrast, PMMA does not contribute significantly to the barrier function as it is highly permeable to oxygen. ${ }^{50}$

Whether or not the 2DM film is continuous has an important impact on the overall process. We will first discuss the case in which a continuous 2DM film acts as a permeation barrier for atmospheric oxygen, which we refer to here as reaction path A. Assuming complete dissociation of $\mathrm{NaOH}$, a $1 \mathrm{M}$ solution has a $\mathrm{pH}$ of 14. The ongoing chemical reaction can be predicted using the Pourbaix diagram for $\mathrm{Cu}^{51}$ Oxidation occurs through the half-reactions given below:

$$
\begin{aligned}
& 2 \mathrm{Cu}+2 \mathrm{OH}^{-} \rightarrow \mathrm{Cu}_{2} \mathrm{O}+\mathrm{H}_{2} \mathrm{O}+2 \mathrm{e}^{-} \text {(anodic reaction) } \\
& \mathrm{O}_{2}+2 \mathrm{H}_{2} \mathrm{O}+4 \mathrm{e}^{-} \rightarrow 4 \mathrm{OH}^{-} \text {(cathodic reaction) }
\end{aligned}
$$

In highly alkaline solutions, cuprous oxide $\left(\mathrm{Cu}_{2} \mathrm{O}\right)$ is not stable. It will corrode by dissolution as cuprite ions $\left(\mathrm{CuO}_{2}{ }^{2-}\right)$ via the following half-reactions:

$$
\begin{aligned}
& \mathrm{Cu}_{2} \mathrm{O}+6 \mathrm{OH}^{-} \rightarrow 2 \mathrm{CuO}_{2}^{(2-)}+3 \mathrm{H}_{2} \mathrm{O}+2 \mathrm{e}^{-} \\
&(\text {anodic reaction) } \\
& \mathrm{O}_{2}+2 \mathrm{H}_{2} \mathrm{O}+4 \mathrm{e}^{-} \rightarrow 4 \mathrm{OH}^{-} \text {(cathodic reaction) }
\end{aligned}
$$

As mentioned in the Results section, when the process temperature is raised to $60{ }^{\circ} \mathrm{C}$, delamination of a $1 \mathrm{~cm} \times 1 \mathrm{~cm}$ 
(a)

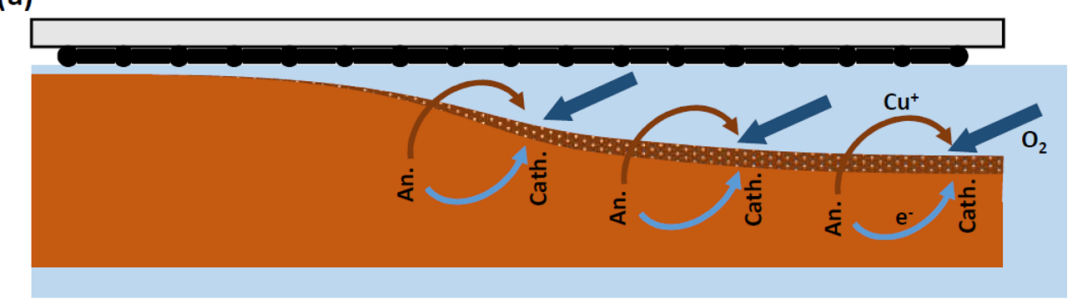

(b)

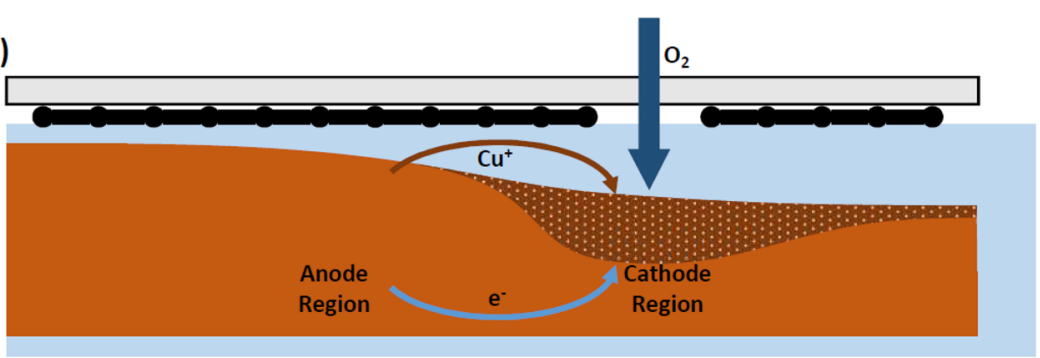

Figure 6. (a) Schematic close-up of the $2 \mathrm{DM} / \mathrm{Cu}$ interface floating on $\mathrm{NaOH}$ during LOT-I transfer. The graphene layer is continuous and acts as a permeation barrier to atmospheric oxygen; i.e., only dissolved oxygen is available as a reactant. Local half cells, i.e., anode regions (An.) and cathode regions (Cath.), are formed over the surface, which results in oxidation progressing uniformly toward the center of the sample. (b) In this case, the graphene layer is not continuous. The gap allows for the passage of atmospheric oxygen to the catalyst surface. The abundance of oxygen establishes the cathode and anode regions. Oxide is preferentially formed at the cathode region.

sample will result after only $2-3 \mathrm{~h}$ as opposed to more than 12 $\mathrm{h}$ for the same process at room temperature. We suggest that the reaction path remains identical but that the process time decreases purely due to thermally increased chemical reaction rates. The process of LOT-I is driven by intercalation, oxidation, and $\mathrm{Cu}$ oxide dissolution. An increase of temperature accelerates the rate limiting step and thus leads to the improved process speed.

A detailed schematic of the $2 \mathrm{DM} / \mathrm{Cu}$ interface is presented in Figure 6a. When the sample is first placed onto the $\mathrm{NaOH}$ solution, the solution will start to intercalate into the interface. It is important to emphasize that intercalation is crucial to the transfer process. If LOT were based on oxidation and dissolution of the oxide only, the result would be equivalent to wet transfer; i.e., the $\mathrm{Cu}$ foil would be completely dissolved. Once the liquid has penetrated the interface, $\mathrm{Cu}$ is oxidized to form cuprous ions $\left(\mathrm{Cu}^{+}\right)$, which then react with oxygen to form $\mathrm{Cu}_{2} \mathrm{O}$. For reaction path A, i.e., atmospheric oxygen is not present, the oxidation will occur uniformly from the edge of the sample toward the center. Previous studies on the oxidation of graphene-covered $\mathrm{Cu}$ have claimed that graphene serves as the cathode for the half-reaction leading to oxidation in aqueous media. ${ }^{34}$ In our experiments, we have shown that LOT-I leads to identical results for h-BN or graphene. This demonstrates that the presence of graphene is not imperative for the cathodic half-reaction; i.e., the corrosion reaction can take place without a conductive $2 \mathrm{DM}$. Instead, we suggest that just as for bare metal surface corrosion in aqueous media, certain regions on the surface act as local anodes and certain others as local cathodes, thus forming local cells for the overall reaction. ${ }^{52}$ However, the presence of graphene can change the spatial distribution of local cells due to its function as a permeation barrier, as will be discussed below.

The quantity and location of $\mathrm{Cu}_{2} \mathrm{O}$ that is formed depends critically on the permeability of the PMMA/2DM stack since PMMA is permeable to oxygen. ${ }^{50}$ In reaction path $\mathrm{A}$, the continuous $2 \mathrm{DM}$ film acts as a permeation barrier. When the $2 \mathrm{DM}$ film is not continuous, atmospheric oxygen can access those regions that are not covered by the $2 \mathrm{DM}$. The reaction changes to what will be called reaction path $\mathrm{B}$. The process in place is schematically depicted in Figure 6b. The given situation is similar to oxygen mediated localized oxide formation in the case of metal corrosion in aqueous media. ${ }^{52}$ A well-known example is the iron oxide formation at the edge of a water droplet on an iron surface. ${ }^{53}$ In our case, the $\mathrm{Cu}$ region without graphene coverage becomes the cathode of the half-reaction due to the local abundance of oxygen. $\mathrm{Cu}$ oxide is now primarily formed at these locations, whereas very little is formed underneath the graphene layer. Indeed, we observe that, during LOT-I transfer, discontinuous graphene layers do not delaminate-not even after numerous days. However, when discontinuous samples are immersed completely in $\mathrm{NaOH}$ instead of floating at the surface (like LOT-I), the duration of transfer is identical to that of continuous layers in LOT-I. We relate this to the fact that the influence of atmospheric oxygen is alleviated when the sample is completely immersed. In order to achieve an even better understanding of the influence of oxygen, future studies could involve LOT-I using degassed electrolytes in an oxygen-free environment or less permeable polymers.

Previous studies have shown that while water-assisted oxidation does facilitate transfer, ${ }^{25,34}$ ultimately delamination does not occur. Therefore, both oxidation and dissolution are of critical importance for LOT-I transfers. In fact, dissolution can be indirectly observed during LOT-I. When a large piece of graphene on $\mathrm{Cu}$ is floated on a small quantity of $1 \mathrm{M} \mathrm{NaOH}$ (e.g., four pieces of $1 \mathrm{~cm} \times 1 \mathrm{~cm}$ in $100 \mathrm{~mL}$ of $1 \mathrm{M} \mathrm{NaOH}$ solution), one can observe that the solution will turn blue after an extended period (about $48 \mathrm{~h}$ ). This can be related to the presence of $\mathrm{CuO}_{2}{ }^{2-}$, which has a blue color. ${ }^{51}$ The solubility of $\mathrm{CuO}_{2}{ }^{2-}$ is only $10^{-6}$ to $10^{-4} \mathrm{M}$ between $\mathrm{pH} 13$ and 14 at room temperature. ${ }^{51}$ We observed that if the quantity of $\mathrm{NaOH}$ solution is not sufficient, as in the example given above, delamination of the 2DM does not occur, despite oxidation of the $\mathrm{Cu}$ foil. 
Besides temperature, the concentration of the solution and thus the $\mathrm{pH}$ also have a major impact on the transfer characteristics and mechanism. The maximum $\mathrm{pH}$ of 15.4 as dictated by the solubility of $\mathrm{NaOH}$, which is $25 \mathrm{M}$, gives an upper limit to the parameter space. In order to find the dependency of LOT-I on the concentration of the solution, experiments were performed at $\mathrm{pH} 15$, i.e., using a $10 \mathrm{M}$ solution. The first consequence of raising the $\mathrm{pH}$ of the solution is the increase in solubility of $\mathrm{CuO}_{2}{ }^{2-}$. However, at extremely high $\mathrm{pH}$, e.g., $\mathrm{pH} 15$, the reaction mechanism itself changes. $\mathrm{Cu}$ will directly dissolve, without the intermediate step of oxidation. The reaction then follows: ${ }^{51}$

$$
\mathrm{Cu}+4 \mathrm{OH}^{-} \rightarrow \mathrm{CuO}_{2}^{(2-)}+2 \mathrm{H}_{2} \mathrm{O}+2 \mathrm{e}^{-}
$$

(anodic reaction)

$$
\mathrm{O}_{2}+2 \mathrm{H}_{2} \mathrm{O}+4 \mathrm{e}^{-} \rightarrow 4 \mathrm{OH}^{-} \text {(cathodic reaction) }
$$

Using $10 \mathrm{M} \mathrm{NaOH}$, we successfully transferred discontinuous graphene layers. We suggest that since dissolution can take place without prior oxidation, localized oxidation plays a smaller role in the overall process.

Compared to LOT-I, the mechanism behind LOT-II is much simpler. It is known that $\mathrm{Cu}$ oxidation under a $2 \mathrm{DM}$ can be achieved by leaving samples under ambient condition for extended periods of time. ${ }^{26,30}$ However, in order to achieve sufficient oxidation in a well-controlled and fast way, we chose to oxidize the $\mathrm{Cu}$ foil in our experiments by immersing the sample in water at $50{ }^{\circ} \mathrm{C}$. The oxidation reaction is the same as for LOT-I without atmospheric oxygen. When the sample is then floated on HCL, the oxide is etched according to the reaction

$$
\mathrm{Cu}_{2} \mathrm{O}+2 \mathrm{H}^{+} \rightarrow 2 \mathrm{Cu}^{+}+\mathrm{H}_{2} \mathrm{O}
$$

As $\mathrm{Cu}$ is stable to hydrochloric acid, the surface oxide is selectively etched.

We demonstrated lift-off transfer of 2DM via LOT-I and LOT-II, which both make use of the same underlying principle of local interfacial oxidation and oxide dissolution. The focus of our discussion has thereby been on the chemical processes at the interface. However, we emphasize that the chemicals used in the transfer process must also be compatible with both the $2 \mathrm{DM}$ and the polymer stack. Previous literature highlights that for wet-transfer, the PMMA contamination can potentially be related to acid (such as $\mathrm{FeCL}_{3}$ ) induced cross-linking. ${ }^{16,43,54}$ With $\mathrm{HCl}$ acid used in combination with PMMA here, the LOT-II process showed a higher degree of surface contamination, despite similar underlying mechanisms. Analogous to prior reports, we suggest that the added residues are potentially a consequence of acid induced cross-linking. $\mathrm{NaOH}$, as used in LOT-I, avoids these acid related detrimental effects on the PMMA, while at the same time enabling the interfacial oxidation. Compatibility with the $2 \mathrm{DM}$ and support layer is an important selection criterion for the process chemicals.

The considerations in this study highlight the applicability but also the limitations of LOT, such as the requirement of intercalation of oxidizing species into the $2 \mathrm{DM} /$ catalyst interface. Systems, where the $2 \mathrm{DM}$ and the catalyst interact strongly, such as $2 \mathrm{DM} /$ nickel $(\mathrm{Ni})$ or $2 \mathrm{DM} /$ iron $(\mathrm{Fe})$, are known to prevent any intercalation of species into the interface, $^{32}$ which makes LOT unlikely to succeed. LOT-I was attempted for h-BN/Ni and h-BN/Fe using a $1 \mathrm{M} \mathrm{NaOH}$ solution at $60{ }^{\circ} \mathrm{C}$. Even after a long period $(>48 \mathrm{~h})$, no effect was observed. However, transfer should be possible for weakly interacting systems such as $2 \mathrm{DM}$ on Pt. In fact, a prior study has demonstrated that when graphene/ $\mathrm{Pt}$ is floated on high $\mathrm{pH}$ solutions at high temperature, delamination will occur. ${ }^{27} \mathrm{We}$ suggest that the main underlying mechanism is similar to the one in LOT-I, i.e., corrosion at the $2 \mathrm{DM} /$ metal interface.

\section{CONCLUSIONS}

The interaction between a $2 \mathrm{DM}$ and its growth catalyst is of crucial importance for all transfer methods that seek to overcome the interfacial adhesion. Weak interaction and weak mechanical adhesion allow for the intercalation of reactive species into the $2 \mathrm{DM} /$ catalyst interface. On the basis of this understanding, we have demonstrated that the interplay between the 2DM and the catalyst is not only important for growth but also decisive for transfer processes. We introduced an approach, referred to here as LOT, which relies on the selective removal of the interface layer between the 2DM and its growth catalyst. While $2 \mathrm{DM}$ are often discussed in the context of corrosion protection, we have shown how targeted corrosion at the interface can actually enable improved transfer.

Overall, we have demonstrated the feasibility of LOT for both graphene and h-BN. The graphene samples that were obtained were characterized by multiple methods, revealing their high quality over a large area. Using FETs made by LOT, we point out the importance of clean processing, as these clearly outperform devices made using larger grain size graphene, but nonideal transfer methods. We also show that h-BN can be easily transferred and demonstrate the cleanliness of the layer. Further experiments based on our rationale, such as LOT-II, highlight the value and usefulness of the understanding of the interfacial processes. It is shown thereby that LOT can serve as a general process approach for improving and ultimately scaling up $2 \mathrm{DM}$ transfer.

\section{EXPERIMENTAL METHODS}

Graphene Growth. Graphene growth was conducted on a $25-\mu \mathrm{m}$ thick $\mathrm{Cu}$ foil with $99.8 \%$ purity (Alfa Aesar). All samples were grown in a commercially available Aixtron Black Magic Pro 4-in. PECVD system. The growth process begins by filling the chamber with a mixture of argon and hydrogen at a ratio of $4: 1(200 \mathrm{sccm} / 50 \mathrm{sccm})$. The temperature is then increased at a rate of $100{ }^{\circ} \mathrm{C} / \mathrm{min}$. The foil is annealed at a growth temperature of $1065^{\circ} \mathrm{C}$ for $30 \mathrm{~min}$ and for large domain graphene samples, for $120 \mathrm{~min}$. The precursor gas mix, which consists of $250 \mathrm{sccm}$ argon, $26 \mathrm{sccm}$ hydrogen, and $9 \mathrm{sccm}$ methane for standard and $7 \mathrm{sccm}$ for large domain graphene $(0.1 \%$ diluted in argon), is then injected into the chamber. The growth time depends on the desired graphene grain size. At all stages of the process, the pressure is kept at 50 mbar. Post-growth, the chamber is cooled naturally to room temperature in an argon only atmosphere.

Graphene grain size control is achieved by a combination of foil pretreatment and growth time variation. For standard grain size graphene $(10-25 \mu \mathrm{m})$, the foil is not pretreated and growth performed over $45 \mathrm{~min}$. Large grain size graphene $(200-400 \mu \mathrm{m})$ is obtained by using electropolished $\mathrm{Cu}$ foils and a growth time of $4 \mathrm{~h}$. The grain size is determined by stopping the respective growth process shortly before the nuclei merge completely to form a complete film and SEM/optical microscope measurement.

h-BN Growth. h-BN growth used processes reported elsewhere. ${ }^{11}$ Two different processes have been used for the samples used in the given studies. For one of these, $25-\mu \mathrm{m}$-thick $\mathrm{Cu}$ foil with $99.8 \%$ purity (Alfa Aesar) was initially cleaned by sonicating in ammonium persulfate and rinsed thoroughly in deionized water. The foil was subsequently heated in $\mathrm{H}_{2}$ to $1050{ }^{\circ} \mathrm{C}$ and annealed for $60 \mathrm{~min}$ in a hot walled furnace. Liquid borazine was used to initiate $\mathrm{h}-\mathrm{BN}$ growth 
for $90 \mathrm{~min}$ and $\mathrm{Cu}$ foil subsequently cooled to room temperature. For the other process, $25-\mu$ m-thick $\mathrm{Cu}$ foil with $99.8 \%$ purity (Alfa Aesar) was directly used for growth. The samples were heated in an Aixtron Black Magic PECVD system in a vacuum to $1000{ }^{\circ} \mathrm{C}$. Liquid borazine was used as the precursor, and growth took place over $5 \mathrm{~min}$, after which the samples were cooled down to room temperature.

Lift-Off Transfer I. Graphene or h-BN on $\mathrm{Cu}$ as received is spincoated with poly(methyl methacrylate) (MicroChem PMMA $950 \mathrm{~K}$ A4) at $3000 \mathrm{rpm}$ for $40 \mathrm{~s}$ resulting in layer of $250 \mathrm{~nm}$ thickness, which is then baked for $90 \mathrm{~s}$ at $180^{\circ} \mathrm{C}$. The sample is then floated on a $1 \mathrm{M}$ solution of $\mathrm{NaOH}$ (Sigma-Aldrich, product number 306576, 99.99\% purity) dissolved in deionized water. At room temperature, the PMMA/2DM stack detaches after about $12 \mathrm{~h}$ for a sample size of $1 \mathrm{~cm}$ $\times 1 \mathrm{~cm}$, at $60{ }^{\circ} \mathrm{C}$ after only $2-3 \mathrm{~h}$. The sample is then rinsed repeatedly with deionized water, transferred onto the target substrate, and dried at $50{ }^{\circ} \mathrm{C}$ for $1 \mathrm{~h}$. In the last step, the polymer is removed by rinsing in acetone and IPA.

Lift-Off Transfer II. Graphene on $\mathrm{Cu}$ is immersed in deionized water and kept at a temperature of $50{ }^{\circ} \mathrm{C}$ for $12 \mathrm{~h}$. The sample is then coated identically to LOT-I and floated on hydrochloric acid (Fisher Scientific, product code $10251183,37 \%$ ) for $5 \mathrm{~min}$, upon which the sample will detach. After rinsing in water, the sample is transferred onto the target substrate and dried at $50{ }^{\circ} \mathrm{C}$ for $1 \mathrm{~h}$ before removing the polymer by acetone and IPA.

Wet Transfer. The samples are spin-coated identically to LOT. The backside graphene is removed with oxygen plasma (oxygen partial pressure of $50 \mathrm{mbar}$, plasma power of $50 \mathrm{~W}$, duration $10 \mathrm{~s}$ ), and $\mathrm{Cu}$ is etched using $0.5 \mathrm{M}$ iron chloride over about $2 \mathrm{~h}$. The remaining transfer process is identical to LOT.

Bubbling Transfer. The samples are spin-coated identically to LOT. The PMMA/2DM/Cu stack was dipped into a $1 \mathrm{M}$ solution of $\mathrm{NaOH}$ and used as the cathode of an electrochemical cell with a $\mathrm{Pt}$ wire as the anode. Transfer was achieved by applying a voltage of $2.3 \mathrm{~V}$ to the cell. The remaining transfer process is identical to LOT.

Optical Characterization. Optical maps were made by capturing and stitching images of the entire sample area at a resolution of $\sim 0.5$ $\mu \mathrm{m} /$ pixel. A combination of normalizing all images for intensity variations and using a high-performance motorized XYZ stage allows us to generate arbitrarily large and high-resolution optical maps.

To calculate the coverage of graphene and the amount of residues, we start by calculating the wavelength-dependent contrast of graphene. ${ }^{55}$ Using the red, green, and blue (RGB) spectral response functions of the CCD sensor, we can obtain the numerical values for pixels of silicon oxide, single layer graphene, as well as bilayer graphene. ${ }^{23}$ Pixels that do not fall into any of these three categories are labeled as residues, and the coverage values presented in this paper thus represent a lower bound, as pixels containing both graphene and residues will only count toward the coverage of residues.

Raman Spectroscopy. All measurements were performed with a commercially available Renishaw Raman system. A $532 \mathrm{~nm}$ laser at a power below $1 \mathrm{~mW}$ was used to avoid graphene damage. Spectra were taken with a $50 \times$ objective lens.

Device Fabrication and Characterization. FETs were fabricated in a two-step photolithography process. The contacts are deposited by sputtering $70 \mathrm{~nm}$ of nickel and subsequent photoresist lift-off. All samples were measured in air directly after processing without additional annealing. The drain current $I_{\mathrm{D}}$ is measured while applying a drain-source voltage $V_{\mathrm{DS}}$ of $10 \mathrm{mV}$ and sweeping the backgate voltage $V_{\mathrm{GS}}$ from $0 \mathrm{~V}$ to $60 \mathrm{~V}$. The maximum transconductance $g_{\mathrm{m}}$ is obtained by fitting the transfer curve. The mobility is calculated using the expression

$$
\mu_{\mathrm{FET}}=\frac{g_{\mathrm{m}} L}{W C_{\mathrm{g}} V_{\mathrm{DS}}}
$$

$W$ and $L$ represent the width and length of the channel, respectively. $C_{\mathrm{g}}$ is the gate capacitance per area, which is $11.6 \times 10^{-9} \mathrm{~F} \mathrm{~cm}^{-2}$ for 300 $\mathrm{nm} \mathrm{SiO}_{2}$.

\section{ASSOCIATED CONTENT}

\section{Supporting Information}

The Supporting Information is available free of charge on the ACS Publications website at DOI: 10.1021/acsami.6b11685.

Raman map of graphene film transferred using wet transfer and electrical properties of FETs (contact resistance) fabricated by LOT-I (PDF)

\section{AUTHOR INFORMATION}

\section{Corresponding Author}

*E-mail:sh315@cam.ac.uk.

ORCID

Ruizhi Wang: 0000-0002-3914-8649

Philipp Braeuninger-Weimer: 0000-0001-8677-1647

Notes

The authors declare no competing financial interest.

\section{ACKNOWLEDGMENTS}

We acknowledge funding from the ERC (InsituNANO, grant 279342). R.W. acknowledges an EPSRC Doctoral Training Award (EP/M506485/1). During this work, S.T. was supported in parts by a DFG research fellowship under grant TA 1122/1-1:1. J.A.A.-W. acknowledges a Research Fellowship from Churchill College, Cambridge. Z.A.V.V. acknowledges funding from ESPRC grant EP/L016087/1. P.B. and B.S.J. thank the Danish National Research Foundation Centre for Nanostructured graphene, DNRF103, and EU Horizon 2020 "Graphene Flagship" 696656. T.J.B. and P.R.W. acknowledge financial support from EU FP7-6040007 "GLADIATOR" and Innovation Fund Denmark Da-Gate 0603-005668B. P.R.K. acknowledges a Lindemann Trust Fellowship. We wish to thank L.d.-J. for checking the manuscript.

\section{REFERENCES}

(1) Ten Years in Two Dimensions. Nat. Nanotechnol. 2014, 9 (10), 725, DOI: 10.1038/nnano.2014.244.

(2) Hofmann, S.; Braeuninger-Weimer, P.; Weatherup, R. S. CVDEnabled Graphene Manufacture and Technology. J. Phys. Chem. Lett. 2015, 6 (14), 2714-2721.

(3) Pakdel, A.; Bando, Y.; Golberg, D. Nano Boron Nitride Flatland. Chem. Soc. Rev. 2014, 43 (3), 934-959.

(4) Caneva, S.; Weatherup, R. S.; Bayer, B.; Brennan, B.; Spencer, S. J.; Mingard, K.; Cabrero-Vilatela, A.; Baehtz, C.; Pollard, A. J.; Hofmann, S. Nucleation Control for Large, Single Crystalline Domains of Monolayer Hexagonal Boron Nitride via Si-Doped $\mathrm{Fe}$ Catalysts. Nano Lett. 2015, 15 (3), 1867-1875.

(5) Oshima, C.; Nagashima, A. Ultra-Thin Epitaxial Films of Graphite and Hexagonal Boron Nitride on Solid Surfaces. J. Phys.: Condens. Matter 1997, 9 (1), 1.

(6) Loginova, E.; Bartelt, N. C.; Feibelman, P. J.; McCarty, K. F. Factors Influencing Graphene Growth on Metal Surfaces. New J. Phys. 2009, 11 (6), 63046.

(7) Bartelt, N. C.; McCarty, K. F. Graphene Growth on Metal Surfaces. MRS Bull. 2012, 37 (12), 1158-1165.

(8) Weatherup, R. S.; Dlubak, B.; Hofmann, S. Kinetic Control of Catalytic CVD for High-Quality Graphene at Low Temperatures. ACS Nano 2012, 6 (11), 9996-10003.

(9) Kim, H.; Saiz, E.; Chhowalla, M.; Mattevi, C. Modeling of the Self-Limited Growth in Catalytic Chemical Vapor Deposition of Graphene. New J. Phys. 2013, 15 (5), 53012.

(10) Kidambi, P. R.; Bayer, B. C.; Blume, R.; Wang, Z. J.; Baehtz, C.; Weatherup, R. S.; Willinger, M. G.; Schloegl, R.; Hofmann, S. Observing Graphene Grow: Catalyst-Graphene Interactions during 
Scalable Graphene Growth on Polycrystalline Copper. Nano Lett. 2013, 13 (10), 4769-4778.

(11) Kidambi, P. R.; Blume, R.; Kling, J.; Wagner, J. B.; Baehtz, C.; Weatherup, R. S.; Schloegl, R.; Bayer, B. C.; Hofmann, S. In Situ Observations during Chemical Vapor Deposition of Hexagonal Boron Nitride on Polycrystalline Copper. Chem. Mater. 2014, 26 (22), 63806392.

(12) Kang, J.; Shin, D.; Bae, S.; Hong, B. H. Graphene Transfer: Key for Applications. Nanoscale 2012, 4 (18), 5527-5537.

(13) Zaretski, A. V.; Lipomi, D. J. Processes for Non-Destructive Transfer of Graphene: Widening the Bottleneck for Industrial Scale Production. Nanoscale 2015, 7 (22), 9963-9969.

(14) Li, X. S.; Cai, W. W.; An, J. H.; Kim, S.; Nah, J.; Yang, D. X.; Piner, R.; Velamakanni, A.; Jung, I.; Tutuc, E.; Banerjee, S. K.; Colombo, L.; Ruoff, R. S. Large-Area Synthesis of High-Quality and Uniform Graphene Films on Copper Foils. Science 2009, 324 (5932), 1312-1314.

(15) Kim, K. S.; Zhao, Y.; Jang, H.; Lee, S. Y.; Kim, J. M.; Kim, K. S.; Ahn, J.-H.; Kim, P.; Choi, J.-Y.; Hong, B. H. Large-Scale Pattern Growth of Graphene Films for Stretchable Transparent Electrodes. Nature 2009, 457 (7230), 706-710.

(16) Pirkle, A.; Chan, J.; Venugopal, A.; Hinojos, D.; Magnuson, C. W.; McDonnell, S.; Colombo, L.; Vogel, E. M.; Ruoff, R. S.; Wallace, R. M. The Effect of Chemical Residues on the Physical and Electrical Properties of Chemical Vapor Deposited Graphene Transferred to SiO2. Appl. Phys. Lett. 2011, 99 (12), 122108.

(17) Lee, J.-H.; Lee, E. K.; Joo, W.-J.; Jang, Y.; Kim, B.-S.; Lim, J. Y.; Choi, S.-H.; Ahn, S. J.; Ahn, J. R.; Park, M.-H.; Yang, C.-W.; Choi, B. L.; Hwang, S.-W.; Whang, D. Wafer-Scale Growth of Single-Crystal Monolayer Graphene on Reusable Hydrogen-Terminated Germanium. Science 2014, 344 (6181), 286-289.

(18) Gao, L.; Ren, W.; Xu, H.; Jin, L.; Wang, Z.; Ma, T.; Ma, L.-P.; Zhang, Z.; Fu, Q.; Peng, L.-M.; Bao, X.; Cheng, H.-M. Repeated Growth and Bubbling Transfer of Graphene with Millimetre-Size Single-Crystal Grains Using Platinum. Nat. Commun. 2012, 3, 699.

(19) Yoon, T.; Shin, W. C.; Kim, T. Y.; Mun, J. H.; Kim, T.-S.; Cho, B. J. Direct Measurement of Adhesion Energy of Monolayer Graphene As-Grown on Copper and Its Application to Renewable Transfer Process. Nano Lett. 2012, 12 (3), 1448-1452.

(20) Wang, Y.; Zheng, Y.; Xu, X.; Dubuisson, E.; Bao, Q.; Lu, J.; Loh, K. P. Electrochemical Delamination of CVD-Grown Graphene Film: Toward the Recyclable Use of Copper Catalyst. ACS Nano 2011, 5 (12), 9927-9933.

(21) Liu, L.; Liu, X.; Zhan, Z.; Guo, W.; Xu, C.; Deng, J.; Chakarov, D.; Hyldgaard, P.; Schröder, E.; Yurgens, A.; Sun, J. A Mechanism for Highly Efficient Electrochemical Bubbling Delamination of CVDGrown Graphene from Metal Substrates. Adv. Mater. Interfaces 2016, 3 (8), 1500492.

(22) Cherian, C. T.; Giustiniano, F.; Martin-Fernandez, I.; Andersen, H.; Balakrishnan, J.; Özyilmaz, B. Bubble-Free" Electrochemical Delamination of CVD Graphene Films. Small 2015, 11 (2), 189-194.

(23) Pizzocchero, F.; Jessen, B. S.; Whelan, P. R.; Kostesha, N.; Lee, S.; Buron, J. D.; Petrushina, I.; Larsen, M. B.; Greenwood, P.; Cha, W. J.; Teo, K.; Jepsen, P. U.; Hone, J.; Bøggild, P.; Booth, T. J. NonDestructive Electrochemical Graphene Transfer from Reusable ThinFilm Catalysts. Carbon 2015, 85, 397-405.

(24) Gupta, P.; Dongare, P. D.; Grover, S.; Dubey, S.; Mamgain, H.; Bhattacharya, A.; Deshmukh, M. M. A Facile Process for Soak-andPeel Delamination of CVD Graphene from Substrates Using Water. Sci. Rep. 2014, 4, 3882.

(25) Yang, S. Y.; Oh, J. G.; Jung, D. Y.; Choi, H.; Yu, C. H.; Shin, J.; Choi, C.-G.; Cho, B. J.; Choi, S.-Y. Metal-Etching-Free Direct Delamination and Transfer of Single-Layer Graphene with a High Degree of Freedom. Small 2015, 11 (2), 175-181.

(26) Banszerus, L.; Schmitz, M.; Engels, S.; Dauber, J.; Oellers, M.; Haupt, F.; Watanabe, K.; Taniguchi, T.; Beschoten, B.; Stampfer, C. Ultrahigh-Mobility Graphene Devices from Chemical Vapor Deposition on Reusable Copper. Sci. Adv. 2015, 1 (6), e1500222.
(27) Choi, J.-K.; Kwak, J.; Park, S.-D.; Yun, H. D.; Kim, S.-Y.; Jung, M.; Kim, S. Y.; Park, K.; Kang, S.; Kim, S.-D.; Park, D.-Y.; Lee, D.-S.; Hong, S.-K.; Shin, H.-J.; Kwon, S.-Y. Growth of Wrinkle-Free Graphene on Texture-Controlled Platinum Films and ThermalAssisted Transfer of Large-Scale Patterned Graphene. ACS Nano 2015, 9 (1), 679-686.

(28) Batzill, M. The Surface Science of Graphene: Metal Interfaces, CVD Synthesis, Nanoribbons, Chemical Modifications, and Defects. Surf. Sci. Rep. 2012, 67 (3), 83-115.

(29) Cabrero-Vilatela, A.; Weatherup, R. S.; Braeuninger-Weimer, P.; Caneva, S.; Hofmann, S. Towards a General Growth Model for Graphene CVD on Transition Metal Catalysts. Nanoscale 2016, 8 (4), 2149-2158.

(30) Schriver, M.; Regan, W.; Gannett, W. J.; Zaniewski, A. M.; Crommie, M. F.; Zettl, A. Graphene as a Long-Term Metal Oxidation Barrier: Worse Than Nothing. ACS Nano 2013, 7 (7), 5763-5768.

(31) Martin, M.-B.; Dlubak, B.; Weatherup, R. S.; Piquemal-Banci, M.; Yang, H.; Blume, R.; Schlögl, R.; Collin, S.; Petroff, F.; Hofmann, S.; et al. Protecting Nickel with Graphene Spin-Filtering Membranes: A Single Layer Is Enough. Appl. Phys. Lett. 2015, 107 (1), 012408.

(32) Weatherup, R. S.; D’Arsié, L.; Cabrero-Vilatela, A.; Caneva, S.; Blume, R.; Robertson, J.; Schloegl, R.; Hofmann, S. Long-Term Passivation of Strongly Interacting Metals with Single-Layer Graphene. J. Am. Chem. Soc. 2015, 137 (45), 14358-14366.

(33) Blume, R.; Kidambi, P. R.; Bayer, B. C.; Weatherup, R. S.; Wang, Z.-J.; Weinberg, G.; Willinger, M.-G.; Greiner, M.; Hofmann, S.; Knop-Gericke, A.; Schlogl, R. The Influence of Intercalated Oxygen on the Properties of Graphene on Polycrystalline $\mathrm{Cu}$ under Various Environmental Conditions. Phys. Chem. Chem. Phys. 2014, 16 (47), 25989-26003.

(34) Wu, R.; Gan, L.; Ou, X.; Zhang, Q.; Luo, Z. Detaching Graphene from Copper Substrate by Oxidation-Assisted Water Intercalation. Carbon 2016, 98, 138-143.

(35) Luo, B.; Whelan, P. R.; Shivayogimath, A.; Mackenzie, D. M. A.; Boggild, P.; Booth, T. J. Copper Oxidation Through Nucleation Sites of Chemical Vapor Deposited Graphene. Chem. Mater. 2016, 28 (11), 3789-3795.

(36) Kidambi, P. R.; Ducati, C.; Dlubak, B.; Gardiner, D.; Weatherup, R. S.; Martin, M. B.; Seneor, P.; Coles, H.; Hofmann, S. The Parameter Space of Graphene Chemical Vapor Deposition on Polycrystalline $\mathrm{Cu}$. J. Phys. Chem. C 2012, 116 (42), 22492-22501.

(37) Aria, A. I.; Kidambi, P. R.; Weatherup, R. S.; Xiao, L.; Williams, J. A.; Hofmann, S. Time Evolution of the Wettability of Supported Graphene under Ambient Air Exposure. J. Phys. Chem. C 2016, 120 (4), 2215-2224.

(38) Oishi, T.; Goto, M.; Kasahara, A.; Tosa, M. Low Frictional Copper Oxide Film Prepared with Sodium Hydroxide Solution. Surf. Interface Anal. 2004, 36 (8), 1259-1261.

(39) Bodas, D. S.; Gangal, S. A. Poly (methyl Methacrylate) as Masking Material for Microelectromechanical System (MEMS) Fabrication. J. Appl. Polym. Sci. 2006, 102 (3), 2094-2098.

(40) Nair, R. R.; Blake, P.; Grigorenko, A. N.; Novoselov, K. S.; Booth, T. J.; Stauber, T.; Peres, N. M. R.; Geim, A. K. Fine Structure Constant Defines Visual Transparency of Graphene. Science 2008, 320 (5881), 1308.

(41) Niaura, G. Surface-Enhanced Raman Spectroscopic Observation of Two Kinds of Adsorbed $\mathrm{OH}-$ Ions at Copper Electrode. Electrochim. Acta 2000, 45 (21), 3507-3519.

(42) Neumann, C.; Reichardt, S.; Venezuela, P.; Drogeler, M.; Banszerus, L.; Schmitz, M.; Watanabe, K.; Taniguchi, T.; Mauri, F.; Beschoten, B.; Rotkin, S. V.; Stampfer, C. Raman Spectroscopy as Probe of Nanometre-Scale Strain Variations in Graphene. Nat. Commun. 2015, 6, 8429.

(43) Song, J.; Kam, F.-Y.; Png, R.-Q.; Seah, W.-L.; Zhuo, J.-M.; Lim, G.-K.; Ho, P. K. H.; Chua, L.-L. A General Method for Transferring Graphene onto Soft Surfaces. Nat. Nanotechnol. 2013, 8, 356-362.

(44) Lin, Y.-C.; Lu, C.-C.; Yeh, C.-H.; Jin, C.; Suenaga, K.; Chiu, P.W. Graphene Annealing: How Clean Can It Be? Nano Lett. 2012, 12 (1), 414-419. 
(45) Lee, G.-H.; Cooper, R. C.; An, S. J.; Lee, S.; van der Zande, A.; Petrone, N.; Hammerberg, A. G.; Lee, C.; Crawford, B.; Oliver, W.; et al. High-Strength Chemical-Vapor-deposited Graphene and Grain Boundaries. Science 2013, 340 (6136), 1073-1076.

(46) Van Veldhoven, Z. A.; Alexander-Webber, J. A.; Sagade, A. A.; Braeuninger-Weimer, P.; Hofmann, S. Electronic Properties of CVD Graphene: The Role of Grain Boundaries, Atmospheric Doping, and Encapsulation by ALD. Phys. Status Solidi B 2016, DOI: 10.1002/ pssb.201600255.

(47) Chavarin, C. A.; Sagade, A. A.; Neumaier, D.; Bacher, G.; Mertin, W. On the Origin of Contact Resistances in Graphene Devices Fabricated by Optical Lithography. Appl. Phys. A: Mater. Sci. Process. 2016, $122(2), 1-5$.

(48) Gorbachev, R. V.; Riaz, I.; Nair, R. R.; Jalil, R.; Britnell, L.; Belle, B. D.; Hill, E. W.; Novoselov, K. S.; Watanabe, K.; Taniguchi, T.; et al. Hunting for Monolayer Boron Nitride: Optical and Raman Signatures. Small 2011, 7 (4), 465-468.

(49) Garcia, A. G. F.; Neumann, M.; Amet, F.; Williams, J. R.; Watanabe, K.; Taniguchi, T.; Goldhaber-Gordon, D. Effective Cleaning of Hexagonal Boron Nitride for Graphene Devices. Nano Lett. 2012, 12 (9), 4449-4454.

(50) Yang, W.-H.; Smolen, V. F.; Peppas, N. A. Oxygen Permeability Coefficients of Polymers for Hard and Soft Contact Lens Applications. J. Membr. Sci. 1981, 9 (1), 53-67.

(51) Pourbaix, M. Atlas of Electrochemical Equilibria in Aqueous Solutions; Pergamon Press, 1966.

(52) Trethewey, K. R.; Chamberlain, J. Corrosion for Science and Engineering; NACE International: Houston, TX, 1988.

(53) Brown, T. E.; LeMay, H. E. H.; Bursten, B. E.; Murphy, C. Chemistry The Central Science, 13th ed.; Prentice Hall, 2014.

(54) Wood, J. D.; Doidge, G. P.; Carrion, E. A.; Koepke, J. C.; Kaitz, J. A.; Datye, I.; Behnam, A.; Hewaparakrama, J.; Aruin, B.; Chen, Y.; et al. Annealing Free, Clean Graphene Transfer Using Alternative Polymer Scaffolds. Nanotechnology 2015, 26 (5), 55302.

(55) Blake, P.; Hill, E. W.; Castro Neto, A. H.; Novoselov, K. S.; Jiang, D.; Yang, R.; Booth, T. J.; Geim, A. K. Making Graphene Visible. Appl. Phys. Lett. 2007, 91 (6), 063124.

(56) Zwick, A.; Carles, R. Multiple-Order Raman Scattering in Crystalline and Amorphous Silicon. Phys. Rev. B: Condens. Matter Mater. Phys. 1993, 48 (9), 6024-6032. 